\title{
Ultraviolet disinfection impacts the microbial community composition and function of treated wastewater effluent and the receiving urban river
}

\author{
Imrose Kauser ${ }^{1}$, Mark Ciesielski $^{1}$, Rachel S Poretsky ${ }^{\text {Corresp. } 1}$ \\ ${ }^{1}$ Department of Biological Sciences, University of Illinois at Chicago, Chicago, IL, United States \\ Corresponding Author: Rachel S Poretsky \\ Email address: microbe@uic.edu
}

Background. In the United States, an estimated 14,748 wastewater treatment plants (WWTPs) provide wastewater collection, treatment, and disposal service to more than 230 million people. The quality of treated wastewater is often assessed by the presence or absence of fecal indicator bacteria. UV disinfection of wastewater is a common final treatment step used by many wastewater treatment plants in order to reduce fecal coliform bacteria and other pathogens; however, its potential impacts on the total effluent bacterial community are seemingly varied. This is especially important given that urban WWTPs typically return treated effluent to coastal and riverine environments and thus are a major source of microorganisms, genes, and chemical compounds to these systems. Following rainfall, stormflow conditions can result in substantial increases to effluent flow into combined systems.

Methods. Here, we conducted a lab-scale UV disinfection on WWTP effluent using UV dosage of 100 $\mathrm{mJ} / \mathrm{cm}^{2}$ and monitored the active microbiome in UV-treated effluent and untreated effluent over the course of $48 \mathrm{~h}$ post-exposure using 16S rRNA sequencing. In addition, we simulated stormflow conditions with effluent UV-treated and untreated effluent additions to river water and compared the microbial communities to those in baseflow river water. We also tracked the functional profiles of genes involved in tetracycline resistance (tetW) and nitrification (amoA) in these microcosms using RT-qPCR.

Results. We showed that while some organisms, such as members of the Bacteroidetes, are inhibited by UV disinfection and overall diversity of the microbial community decreases following treatment, many organisms not only survive, but remain active. These include common WWTP-derived organisms such as Comamonadaceae and Pseudomonas. When combined with river water to mimic stormflow conditions, these organisms can persist in the environment and potentially enhance microbial functions such as nitrification and antibiotic resistance. 
1 Ultraviolet disinfection impacts the microbial community composition and function of

2 treated wastewater effluent and the receiving urban river.

5 Imrose Kauser ${ }^{1}$, Mark Ciesielski ${ }^{1}$, and Rachel S. Poretsky ${ }^{1}$

6

$7 \quad{ }^{1}$ Department of Biological Sciences, University of Illinois at Chicago, Chicago, IL, USA.

8

9 Corresponding Author:

10 Rachel Poretsky

11950 S. Halsted St, 4100a SELE, MC 067, Chicago, IL 60607

12 Email address: microbe@uic.edu

13

14 


\section{Abstract}

16 Background. In the United States, an estimated 14,748 wastewater treatment plants (WWTPs)

17 provide wastewater collection, treatment, and disposal service to more than 230 million people.

18 The quality of treated wastewater is often assessed by the presence or absence of fecal indicator

19 bacteria. UV disinfection of wastewater is a common final treatment step used by many

20 wastewater treatment plants in order to reduce fecal coliform bacteria and other pathogens;

21 however, its potential impacts on the total effluent bacterial community are seemingly varied.

22 This is especially important given that urban WWTPs typically return treated effluent to coastal 23 and riverine environments and thus are a major source of microorganisms, genes, and chemical

24 compounds to these systems. Following rainfall, stormflow conditions can result in substantial 25 increases to effluent flow into combined systems.

26 Methods. Here, we conducted a lab-scale UV disinfection on WWTP effluent using UV dosage

27 of $100 \mathrm{~mJ} / \mathrm{cm}^{2}$ and monitored the active microbiome in UV-treated effluent and untreated

28 effluent over the course of $48 \mathrm{~h}$ post-exposure using $16 \mathrm{~S}$ rRNA sequencing. In addition, we

29 simulated stormflow conditions with effluent UV-treated and untreated effluent additions to river

30 water and compared the microbial communities to those in baseflow river water. We also tracked

31 the functional profiles of genes involved in tetracycline resistance (tet W) and nitrification ( $a m o A)$

32 in these microcosms using RT-qPCR.

33 Results. We showed that while some organisms, such as members of the Bacteroidetes, are

34 inhibited by UV disinfection and overall diversity of the microbial community decreases

35 following treatment, many organisms not only survive, but remain active. These include

36 common WWTP-derived organisms such as Comamonadaceae and Pseudomonas. When

37 combined with river water to mimic stormflow conditions, these organisms can persist in the 
38 environment and potentially enhance microbial functions such as nitrification and antibiotic

39 resistance.

\section{Introduction}

Wastewater treatment plants (WWTP) treat residential and industrial waste and return

effluent to natural systems. In the United States, $\sim 20 \%$ of regulated effluent released from

WWTPs enter water bodies that can be classified as effluent dominated, i.e., where effluent

discharge comprises the majority of the flow (Brooks et al. 2006). Rivers that flow through cities

are often used as receiving bodies for WWTP effluent, which typically introduces nutrients,

compounds of emerging concern, and microorganisms to these systems (Abraham 2011).

Assessing the effects of effluent discharge on receiving waterways is of considerable

environmental consequence, especially in areas under the influence of high population pressure

and stress to the health of freshwater systems. In particular, WWTP effluent can potentially impact microbial community diversity, structure, and metabolic potential. The effects of effluent discharge on nutrient loading (Waiser et al. 2011), chemical loading (Garcia-Armisen et al. 2005;

Ramond et al. 2009; Schlüter et al. 2007), eutrophication (Gücker et al. 2006), and microbial communities (Chu et al. 2018; Drury et al. 2013; Goñi-Urriza et al. 1999; Price et al. 2018) have been investigated and show far-reaching impacts for the dissemination of compounds, genes, and organisms. For example, in a recent study of two WWTPs in Wisconsin, USA, we estimated that $\sim 30 \times 10^{12}$ bacterial cells per day are released from each plant's effluent into Lake Michigan, despite removal of most bacterial biomass (Chu et al. 2018; Petrovich et al. 2018). Futhermore, 
61 discharge from WWTPs that handle stormwater (Chaudhary et al. 2018; Meziti et al. 2016).

62 Despite this, the primary method for assessing WWTP discharge water quality in the United

63 States continues to rely on measuring fecal indicator bacteria (FIB) and largely ignores other

64 microorganisms, genes, and many chemical contaminants (United States Environmental

65 Protection Agency 2018).

66 Each stage of wastewater treatment has the potential to alter the microbial community

67 from the influent to the final effluent (Petrovich et al. 2018). The final treatment method used in

68 the WWTP is one of the major influences on the microbial community composition and activity

69 of effluent discharge. Secondary treatment, which removes at least $85 \%$ of biological oxygen

70 demand and total suspended solids from the influent wastewater, is the minimum level that must

71 be achieved for discharges from all municipal WWTPs under the Clean Water Act. Tertiary

72 treatment and disinfection using chemical (commonly chlorine, chloramine, or ozone) or

73 physical (e.g., ultraviolet light) processes is used by nearly every major municipal WWTP;

74 however, according to the EPA Clean Watersheds Needs Survey ( United States Environmental

75 Protection Agency 2009), approximately 50\% of the US population is serviced by municipal

76 WWTPs that do not provide more than secondary treatment and release effluent that has not been

77 disinfected into the environment. The number of WWTPs that employ post-secondary treatment,

78 including disinfection, is projected to increase by 2028. UV disinfection primarily works by

79 damaging dsDNA and forming toxic photooxidation by-products that kill or damage

80 microorganisms prior to effluent discharge (Liang et al. 2012). It is possible that this reduction in

81 microbial load also reduces the input of specialized genes that are involved in biodegradation

82 processes and/or enriches the community in UV-tolerant organisms, thus shifting the metabolic

83 potential and microbial community diversity in the environment. Indeed, there is some evidence 
84 that UV treatment modifies the bacterial community in wastewater (Kulkarni et al. 2018) and can

85 enrich for some antibiotic resistant bacteria and genes in effluent, while removing others (Di

86 Cesare et al. 2016; Guo et al. 2013b; Narciso-da-Rocha et al. 2018). These previous studies

87 focused on the microbial community composition, which includes active as well as inactive

88 organisms, or specific functions such as antibiotic resistance.

89 Here, we examined the potential effects of UV disinfection on the active microbial

90 community in wastewater effluent as well as its impacts on the receiving riverine community by

91 targeting the 16S rRNA and multiple functional genes in the community RNA fraction. Unlike

92 previous studies on UV disinfection that assessed functional changes using microbial cultivation

93 after UV exposure with a focus on pathogens (Di Cesare et al. 2016; Guo et al. 2013b; Kulkarni

94 et al. 2018; Narciso-da-Rocha et al. 2018), we monitored the active microbial community with

95 16S rRNA to make predictions about potential ecosystem-level impacts of disinfection based on

96 microcosm incubations. We focused on effluent from the Terrence J. O’Brien Water

97 Reclamation Plant, Chicago, IL, (abbreviated O'Brien WWTP from here on), which discharges

98 into the Chicago River Waterways. Effluent from the O’Brien WWTP has previously been

99 shown to impact water quality (in terms of nitrogen and phosphorus) and microinvertebrate

100 composition (Polls et al. 1980) as well as microbial community composition (Chaudhary et al.

101 2018) in this system. Until recently, the Chicago area remained the largest municipality in the

102 US that did not disinfect WWTP effluent prior to release into the environment, providing a

103 unique opportunity to assess potential impacts of disinfection; disinfection of O'Brien WWTP

104 effluent using UV treatment began in 2016. We carried out a lab-scale UV disinfection

105 experiment prior to the implementation of this post-secondary treatment in order to evaluate how

106 the effluent bacterial community changes after UV disinfection. We also compared mock 
107 stormflow and baseflow conditions in microcosms with effluent and river water to make

108 predictions about how UV disinfection might impact the river community under these

109 conditions. Despite extensive work studying the effects of disinfection on microbial communities

110 in effluent (Di Cesare et al. 2016; Guo et al. 2013b; Kulkarni et al. 2018; Narciso-da-Rocha et al.

111 2018), comparatively little is known about how this impacts microbial community composition

112 and functional potential in receiving waters. We used a combination of phylogenetic and

113 functional-gene-based molecular approaches to investigate the composition and diversity of the

114 effluent, the functional ecology of the effluent-receiving river, and the fate and persistence of

115 bacteria subjected to UV disinfection. Shifts in the diversity and composition of the effluent

116 community over 48 hours from UV exposure were observed. We used both inferred functions

117 and quantitative PCR (qPCR) of specific functional genes associated with nitrification (amoA)

118 and antibiotic resistance (tet $W$ ) in order to understand potential functional and ecosystem-level

119 implications of UV disinfection. We demonstrate that different microorganisms respond

120 differently to UV exposure and many bacteria survive and persist even after disinfection,

121 including sewage specific Arcobacter as well as a variety of Beta- and Gammaproteobacteria.

122 Our results can be used to predict the environmental implications of full-scale disinfection at the

123 O'Brien WWTP as well as shed some light on the effects of this widely used disinfection

124 process.

125

126 Materials \& Methods

127 Site and sample description

128 The O'Brien WWTP on the North Shore Channel (NSC) of the Chicago River is one of the three

129 largest WWTPs in the Chicago metropolitan area. The O'Brien WWTP has an average design 
130 flow of 333 million gallons per day (MGD) and a maximum of 450 MGD. It serves over

1311.3 million people residing in $\sim 365 \mathrm{~km}^{2}$, which includes the northern portion of Chicago and

132 northern suburbs. It uses secondary treatment with waste-activated sludge processes and, at the

133 time of this study, released an average of 0.787 million $\mathrm{m}^{3}$ per day of treated but non-disinfected

134 wastewater effluent into the NSC. The Chicago River system of channels and canals flows

135 through a highly urbanized area with water inputs mainly from domestic pumpage and storm

136 water runoff. According to US Environmental Protection Agency estimates, upwards of 70\% of

137 the Chicago River is comprised of wastewater and is often closer to $90 \%$ under stormflow

138 conditions (Illinois Department of Resources 2011). O’Brien WWTP effluent and Chicago River

139 samples (5-10L) were collected in July 2014. Grab samples of the effluent from the WWTP

140 discharge point and the river water $1 \mathrm{~km}$ downstream from the WWTP discharge point were

141 collected using a horizontal sampler (Wildco, Yulee, FL). All samples were stored on ice for

142 transport back to the laboratory for subsequent experimental manipulations.

\section{Disinfection procedure and experimental manipulations}

145 A bench-scale collimated beam apparatus design and dosage calculations were carried as

146 described elsewhere (Bolton \& Linden 2003). The apparatus contained a monochromatic low-

147 pressure $(15 \mathrm{~W}) \mathrm{UV}$ lamp housed in a dark enclosure. Effluent (1 L) was put under the

148 collimated beam and gently stirred throughout the UV exposure time, which corresponded to a

149 UV dosage of $100 \mathrm{~mJ} / \mathrm{cm}^{2}$. This fluence was chosen because it exceeds the municipality's

150 standard requirements (Metropolitan Water Reclamation District of Greater Chicago. 2011) and

151 is similar to the minimum recommended UV dose for the treatment of drinking water in the

152 United States (Linden et al. 2002). Replicates of $100 \mathrm{~mL}$ microcosms with the UV-treated 
153 effluent or the untreated effluent were simultaneosuly incubated in the dark at room temperature

$154\left(25 \pm 2{ }^{\circ} \mathrm{C}\right)$ with gentle agitation $(<200 \mathrm{rpm})$. Two microcosms were sacrificed for nucleic acid

155 extractions at each timepoint: $2 \mathrm{~h}, 24 \mathrm{~h}$, and $48 \mathrm{~h}$. To further assess environmental implications,

$15650 \mathrm{~mL}$ of either UV-treated effluent or untreated effluent were mixed with $50 \mathrm{~mL}$ of river water

157 and incubated as above. Unamended river samples reflect the river under baseflow conditions,

158 where WWTP effluent contributes to $\sim 70 \%$ of the flow. The $50 \mathrm{~mL}$ amendments represent

159 stormflow conditions of close to $90 \%$ effluent flow.

160

161 Filtration and RNA extraction

162 At each timepoint, water/effluent samples were pre-filtered using $1.7 \mu \mathrm{m}$ glass fiber filters

163 (Whatman, Pittsburgh, PA) and cells were collected on $0.2 \mu \mathrm{m}$ polycarbonate filters (EMD

164 Millipore, Billerica, MA). Filters were stored in $-80^{\circ} \mathrm{C}$ until RNA extraction. An organic

165 extraction method was performed as follows: $1.15 \mathrm{mg} / \mathrm{ml}$ lysozyme in lysis buffer buffer (50

$166 \mathrm{mM}$ Tris- $\mathrm{HCl}, 40 \mathrm{mM}$ EDTA, and $0.73 \mathrm{M}$ sucrose) was added to the filters and incubated at

$16737^{\circ} \mathrm{C}$ for $30 \mathrm{~min}$ on a rotator. The lysates were subsequently incubated with $1 \%$ SDS and 10

$168 \mathrm{mg} / \mathrm{ml}$ proteinase $\mathrm{K}$ for $2 \mathrm{~h}$ at $55^{\circ} \mathrm{C}$ while rotating. RNA was extracted from lysate with acid

169 phenol and chloroform, and isolated via ethanol precipitation followed by suspension in TE

170 buffer. DNase treatment was performed using the RTS DNase kit (MoBio Laboratories,

171 Carlsbad, CA) following the manufacturer's instructions. RNA (500ng-1 $\mu \mathrm{g})$ was transcribed into

172 cDNA with High Capacity RNA-to-cDNA kit (Life Technologies, Carlsbad, CA) according to

173 manufacturer's instructions.

174

$17516 S$ rRNA amplicon sequencing 
176 For amplicon sequencing of the small subunit ribosomal RNA (SSU rRNA) of bacteria, primers

177 27F (Frank et al. 2008), and 534R (Jumpstart Consortium Human Microbiome Project Data

178 Generation Working 2012) were used to target and amplify the V1-3 hypervariable region. PCR

179 reactions were prepared with $12.5 \mu 1$ Accuprime Supermix II (Life Technologies, Carlsbad, CA),

$180500 \mathrm{nM}$ final concentration of each primer, $10-50 \mathrm{ng}$ of cDNA, and water was added to a final 25

$181 \mu \mathrm{l}$ volume. Thermal conditions for PCR were as follows: $95^{\circ} \mathrm{C}$ for 5 minutes, followed by 28

182 cycles of $95^{\circ} \mathrm{C}$ for $30 \mathrm{~s}, 56^{\circ} \mathrm{C}$ for $30 \mathrm{~s}$ and $68^{\circ} \mathrm{C}$ for $5 \mathrm{~s}$. A final, 7-minute elongation step was

183 performed at $68^{\circ} \mathrm{C}$. PCR product size was confirmed with $1 \%$ agarose gel. Paired-end amplicon

184 sequencing ( 2 × 300 bp) was done at the UIC DNA Services laboratory using the Illumina MiSeq

185 platform, which yielded 26,537-48,074 reads per sample. All sequences have been deposited in

186 the Sequence Read Archive under accession number SRP153092.

Bacterial composition and function predictions

189 The quality of reads was assessed using FastQC (Andrews 2012) and reads were trimmed for

190 low-quality regions and primers using Trimmomatic (Bolger et al. 2014). Filtering, chimera

191 checking, clustering, and taxonomy assignment were conducted using the Quantitative Insights

192 Into Microbial Ecology (QIIME, v1.8.0) (Caporaso et al. 2010). Although paired-end reads were

193 obtained, these did not pair well, likely due to length variability in the 27F-534R region that

194 results in assembly of shorter fragments but not longer ones. Because of this, further analysis

195 was only performed on the trimmed forward reads. Forward reads were quality trimmed and

196 chimeric sequences were identified and removed with UCHIME using the de novo method

197 (Edgar et al. 2011). Sequences were binned into Operational Taxonomic Units (OTUs) using

198 usearch v. 7.0.109 (default settings) and the OTU table was filtered by removing OTUs with 
$199<0.005 \%$ of the total number of sequences and with no more than $15 \%$ of the samples being

200 represented by singletons. Taxonomy was assigned following the closed reference OTU method

201 where reads were clustered at $97 \%$ identity to a pre-existing Greengenes reference database

202 (v13.8). Phylogenetic Investigation of Communities by Reconstruction of Unobserved States

203 (PICRUST) v. 1.1.3 (Langille et al. 2013) was used to predict functions from the 16S rRNA 204 datasets.

205

206

Statistical analyses

207 Permutational multivariate analysis of variance (PERMANOVAs) were carried out in R (Adonis 208 function, vegan package v. 2.4-4) using Bray-Curtis OTU-based distance matrices to test the 209 effect of the factors of time, UV disinfection, and stormflow vs. baseflow-like conditions.

210 DESeq2 analysis (Love et al. 2013) was carried out using code from the Phyloseq (McMurdie \&

211 Holmes 2013) tutorial "Using Negative Binomial in Microbiome Differential Abundance

212 Testing," including the calculation of geometric means prior to DESeq2 testing to account for

213 zero values. This method was used to identify differential abundances of taxa between treatments

214 and is well-suited to experiments with low replication (Love et al. 2013). One-way Analysis of

215 Variances (ANOVA) were run to test the effect of treatment on diversity. Additionally, we used

216 linear discriminant analysis effect size (LEfSe) (Segata \& Huttenhower 2011) to compare the

217 estimated phylotypes and identify the most differentially abundant taxa between different

218 treatments with a moderately stringent effect size threshold of 2 (Segata et al. 2011). Taxonomic

219 and functional profiles were compared using Statistical Analysis of Metagenomic Profiles

220 (STAMP) (Parks et al. 2014). ANOVA and Tukey's 'Honest Significant Difference' tests were

221 used to evaluate the qPCR-based gene expression between samples using the TukeyHSD() 
222 function in R. Random Forest models were used for supervised learning (Knights et al. 2011)

223 using the supervised_learning.py script in QIIME with 1,000 trees and 10-fold cross validation.

224 All statistical analyses were assessed for significance using an alpha level of 0.05.

225

226 Quantification of gene expression

227 For detailed functional analyses, we focused on ammonia oxidation and tetracycline resistance.

228 Real-time PCR analyses were performed according to MIQE guidelines. RT-qPCR of the

229 bacterial ammonia monooxygenase (amoA) gene was conducted using primers AmoA-1F and

230 AmoA-2R (Rotthauwe et al. 1997) on a Bio-Rad CFX96 instrument. Each reaction was

231 performed in triplicate in a final volume of $20 \mu$ l containing $10 \mu 1$ Power SYBR green PCR

232 master mix (Life Technologies, Carlsbad, CA), $0.5 \mu \mathrm{M}$ final concentration of each primer, $2 \mu 1$

233 of 1:4 diluted cDNA template, and RNAse-free water. PCR amplification was initiated at $95^{\circ} \mathrm{C}$

234 for $30 \mathrm{~s}$ followed by 40 cycles of denaturation at $95^{\circ} \mathrm{C}$ for $15 \mathrm{~s}$, primer annealing at $53^{\circ} \mathrm{C}$ for 30

$235 \mathrm{~s}$, extension at $72^{\circ} \mathrm{C}$ for $1 \mathrm{~min}$, and plate read. The product specificity was confirmed

236 by melting curve analysis $\left(60-98^{\circ} \mathrm{C}, 0.5^{\circ} \mathrm{C}\right.$ per read, $30 \mathrm{~s}$ hold). Expression of the tetracycline

237 resistance gene tet $\mathrm{W}$ was quantified using primers from (Aminov et al. 2001; Walsh et al. 2011).

238 Thermal cycling was as described above but with an annealing temperature of $64^{\circ} \mathrm{C}$. Transcript

239 levels of all the genes were calculated by relative quantification using the $\Delta \Delta \mathrm{CT}$ method (Livak

240 \& Schmittgen 2001), with rpoB gene as the normalizing gene (Dahllof et al. 2000). Cq values

241 were converted to numerical values using the following formula: $\log 2^{\text {-(mean } \mathrm{Cq} r p o B}$ - mean Cq target 242 gene).

244 Results 


\section{Effect of disinfection of effluent on bacterial diversity}

246 We analyzed the 16S rRNA composition in UV-disinfected and control effluent

247 microcosms over $48 \mathrm{~h}$ in order to evaluate shifts in the active microbial community in response

248 to disinfection. We used this RNA-based approach to account for DNA that might be present but

249 no longer viable following UV exposure and should therefore reflect the active microbial

250 response to treatment (De Vrieze et al. 2018). Alpha diversity was assessed in the context of both

251 evenness (Shannon Index) and richness (observed species) and compared across both treatment

252 and time using ANOVA. Samples all had between 225-358 distinct OTUs. Overall, the changes

253 in alpha diversity were generally small with alpha diversity (Shannon Index) between 3.0-5.0 for

254 all five treatments. As expected, UV treatment resulted in a decrease in observed OTUs and

255 reduced microbial diversity measured in terms of Shannon diversity, relative to the untreated

256 effluent (Fig. 1). This was particularly evident after 48h, when alpha diversity in the untreated

257 effluent increased from $24 \mathrm{~h}$ prior but did not change in the UV treated effluent. In fact, despite a

258 decrease in observed OTUs by an average of 73 OTUs between 24 and 48h, neither diversity

259 metric changed significantly over time in the UV-treated samples, but both increased between

260 the beginning of the experiment and $48 \mathrm{~h}$ for the non-treated effluent samples (non-parametric t-

261 test $p=0.045$, observed species and $p=0.032$, Shannon). Furthermore, the overall diversity was

262 lower in the UV-treated samples relative to the control, although this was not deemed significant.

263 Compositional change was assessed based on Bray-Curtis distance and showed that the microbial

264 communities in both the untreated and UV treated effluent samples changed over time, but in

265 different ways (Fig. 2A). Specifically, the Bray-Curtis distances between treated and UV-treated

266 effluent samples were different when all timepoints, including time 0 , were considered together

267 (PERMANOVA $\mathrm{p}=0.025)$. Further, the differences between community composition were 
268 significant over time for both treated and untreated effluent, as well as between treated and

269 untreated effluent at $24 \mathrm{~h}$ and $48 \mathrm{~h}$ (PERMANOVA $\mathrm{p}=0.001$ ). Random Forest models used for

270 supervised learning demonstrated that whether the sample was UV treated or not was more

271 predictive of the community composition (Ratio of baseline error to observed error $=5.45$ ) than

272 was time.

273

274

\section{Effect of disinfection on effluent bacterial community composition}

In all effluent samples, Bacteroidetes and Proteobacteria were the dominant phyla, with

Bacteriodetes, primarily characterized by the families Cytophagaceae and Flavobacteriaceae,

decreasing in relative abundance over time in the UV-treated effluent. In the untreated effluent,

Alphaproteobacteria increased and Betaproteobacteria decreased in relative abundance over time

(Fig. 3). The dominant Betaproteobacteria were either unclassified ( $\sim 16 \%$ of total OTUs) or

members of the families Comamonadaceae ( $20 \%)$ and Procabacteriaceae ( 18\%) (Fig. S1).

281 Other abundant families were Verrucomicrobiaceae ( $5 \%)$, members of the Bacteroidetes

282 Flavobacteriaceae ( 7\%), ACK-M1 ( 7\%), and Cytophagaceae ( 5\%) (Fig. S1).

283 Pelagibacteraceae were the most abundant alphaproteobacterial family ( 3\%). (Fig. S1).

284 In order to determine which taxa were most characteristic of the differences between the

285 untreated and UV-treated effluent (all timepoints combined), we used LDA Effect Size (LEfSe).

286 Many OTUs decreased in relative abundance in the UV-treated effluent compared to the

287 untreated effluent samples. These included an OTU most closely associated with the

288 Sediminibacterium genus, relatives of which are common in freshwater and engineered systems

289 such as activated sludge (Ayarza et al. 2014), as well as numerous OTUs affiliated with the

290 Rhodobacteraceae and Flavobacteriaceae families. However, a number of organisms were 
291 significantly enriched following UV exposure. These included members of the Proteobacteria,

292 families Chromatiaceae and Moraxellaceae, and genera most closely related to Rheinheimera,

293 Hydrogenophaga, Pseudomonas, Rhodoferax (Fig. 4A). DeSeq2 analysis further identified

294 OTUs belonging to the families Comamonadaceae, Chromatiaceae, Pseudomonadaceae,

295 Methylophilaceae, Rhodocyclaceae, and Procabacteriaceae that were specifically enriched $48 \mathrm{~h}$

296 following UV exposure compared to the untreated effluent (Table S1). These same families

297 significantly increased in abundance in the UV-exposed effluent over time (Table S1). By

298 contrast, few OTUs changed in abundance over the course of the $48 \mathrm{~h}$ incubation in the untreated

299 control effluent (Table S1).

300 In order to determine if the persistence of any organisms in the UV-treated effluent were

301 fecal indicators, we examined the trends among organisms that are typically identified as

302 coliforms and fecal enterococci, which include the genera Enterobacter, Klebsiella, Citrobacter,

303 and Escherichia and other sewage indicator bacteria such as Arcobacter (Fisher et al. 2014), and

304 compared their abundances to the untreated control effluent. Only 72 OTUs were assigned to

305 taxa that matched these indicator bacteria: members of the orders Sphingomonadales (53) and

306 Enterobacteriales (1), the genera Dechloromonas (1), Arcobacter (13), Acinetobacter (2), and

307 Legionella (2). Of these, only two Sphingomonadales that were between 5-15 times less

308 abundant in the UV-treated than the untreated effluent were significantly different (all timepoints

309 combined based on DeSeq analysis, $p=0.000034$ and 0.011 ). Eleven OTUs affiliated with three

310 Arcobacter OTUs and the two Legionella OTUs were actually more abundant in the UV-treated

311 effluent samples, although these all generally decreased over time in the incubations in both

312 conditions. This decrease, however, was not significant (Kruskall-Wallace test, $p=0.84$ for

313 Legionella OTU and 0.56 for Arcobacter; Table S2). 


\section{Effect of $U V$ disinfection on the river under stormflow conditions}

316 Discharge of effluent from WWTPs is often a major source of stream-flow and chemical

317 flux is many systems, but stormflow conditions can increase this WWTP-derived flow, thus

318 impacting the microbial communities. In particular, WWTPs in the Chicago Area Waterways

319 comprises more than $70 \%$ treated municipal wastewater effluent in baseflow conditions and up

320 to $90 \%$ under stormflow conditions (USGA National Water Information System for North Shore

321 Channel USGS 05536101 and (Illinois Department of Resources 2011)). Given the substantial

322 influence of WWTP effluent in this system, we evaluated the impact of UV disinfection on the

323 riverine microbial community into which it is discharged by combining either the UV-treated or

324 untreated effluent with NSC river water at a ratio that mimics the $\sim 90 \%$ effluent stormflow.

325 Although these microcosms do not necessarily reflect actual, system-wide effects, our

326 observations allow us to make predictions about what might happen under stormflow conditions.

327 Despite the predominance of effluent in baseflow NSC river water, the river communities

328 differed from the effluent communities in terms of both alpha diversity (Fig. 1) and composition

329 (Table S1, Fig. 3), similar to what we observed previously (Chaudhary et al. 2018). The river

330 samples had significantly higher alpha diversity (Shannon) than the effluent samples (non-

331 parametric t-test $\mathrm{p}=0.04)$. Proteobacteria and Bacteroidetes dominated both river and effluent

332 samples, but river samples were also characterized by a high abundance of Actinobacteria (up to

$333 \sim 13 \%$ of the river OTUs) and Verrucomicrobia (up to $\sim 10 \%$ of the river OTUs); both of these

334 phyla contributed to $<1 \%$ of the total effluent OTUs. Both phyla were primarily associated with

335 the aquatic genera: Prosthecobacter and ACK-M1 (Fig. S1, Fig. S2) 

stormflow samples were significantly different when all timepoints were considered together (PERMANOVA $\mathrm{p}=0.003$ ), regardless of whether or not the effluent was UV-treated. In fact,

341 there was no significant difference between the stormflow samples with UV-treated vs. untreated

342 effluent addition (PERMANOVA p =0.102). This similarity in overall community composition

343 between the stormflow samples persisted over the course of the experiment with both stormflow

344 treatments shifting in community composition significantly over time (PERMANOVA p=0.001)

345 in the same way for both UV-treated effluent and untreated effluent stormflow samples (Fig.

346 2B). Only after $48 \mathrm{~h}$ did the community composition of two stormflow treatments begin to

347 diverge from one another. The microbial community of the baseflow river samples did not 348 change significantly over time (PERMANOVA $\mathrm{p}=0.067)$. the differences between the baseflow, untreated, and UV-treated effluent stormflow samples (all

351 timepoints combined). Among the taxa that were more prevalent in the baseflow river water

352 were members of the Actinobacteria as well as some common freshwater organisms including

353 members of the families ACK-M1 and Pelagibacteraceae and the genus Polynucleobacter (Fig.

354 4B). Many taxa contributed significantly to differences in the stormflow samples with untreated 355 effluent including fecal indicator members of the phylum Bacteroidetes, families

356 Enterobacteriaceae and Legionellaceae, and genus Arcobacter (Fig. S2). The families

357 Rhodocyclaceae and Oxalobacteraceae were the only groups driving differences in the UV-

358 treated effluent stormflow water (Fig. S1). 
At the end of the incubation experiment, DeSeq2 analysis showed similar taxa that were

360 enriched in both stormflow treatments relative to the baseflow sample (Table S1). These

361 included members of the families Rhodocyclaceae, Cytophagaceae, Flavobacteriaceae,

362 Verrucomicrobiaceae and Procabacteriaceae. After 48h, the UV-treated stormflow samples

363 were also enriched in a Campylobacteraceae OTU whereas the untreated stormflow samples

364 were enriched in a Cryomorphaceae OTU relative to baseflow. Interestingly, baseflow samples

365 were enriched in an OTU attributed to Pelagibacteraceae relative to both stormflow samples.

366 Only four OTUs were significantly different between the two stormflow treatments at 48h; these

367 included members of the families Cryomorphaceae, Flavobacteriaceae, and the order

368 Sphingobacteriales, which were all more than twice as abundant in UV-treated compared to

369 untreated effluent stormflow.

370

\section{Potential functional attributes}

Based our previous observations of tetracycline resistance genes and ammonia oxidation

373 genes in metagenomic datasets from both the O'Brien WWTP effluent and NSC river water

374 (Chaudhary et al. 2018), we hypothesized that these functions could be affected by UV

375 treatment. In addition, although the present 16S rRNA amplicon-based study focuses on

376 microbial community composition rather than function, PICRUST analysis of the 16S rRNA

377 datasets indicated possible differences in several functions, including antimicrobial resistance

378 (more abundant in untreated effluent compared to UV-treated effluent, Welch's t-test $\mathrm{p}=0.045$,

379 Fig. S3). We therefore used RT-qPCR to track the shifts in expression of a tetracycline resistance

380 gene, tet $W$, and a bacterial ammonia oxidation gene, amo $A$, in order to evaluate if UV

381 disinfection could change the expression levels of these genes and thus, whether there might be a 
382 potential for other functional shifts. tet $W$ expression was significantly higher in the untreated

383 effluent than in the UV-treated effluent (ANOVA $\mathrm{p}=0.0006$ ) (Fig. 5A). This same pattern was

384 seen for bacterial amo $A$ gene expression, although by $48 \mathrm{~h}$ amoA expression levels were no

385 different between the effluents (Fig. 5A). Gene expression of both of these genes increased

386 slightly over time in the effluents, although this increase followed an initial decrease in the

387 effluent samples exposed to UV. In contrast, tet $W$ gene expression was higher in the river

388 samples with UV-treated effluent (ANOVA $\mathrm{p}=0.016)($ Fig. 5B) and significantly increased in

389 the river over time after the UV-treated effluent addition (Welch's t-test $p=0.034$ ), but did not

390 change over time in the river with untreated effluent (Fig. 5B). Bacterial amoA gene expression

391 between river samples with both the untreated or UV-treated effluent was generally similar at all

392 three timepoints.

393

\section{Discussion}

395 A variety of bacteria survive and remain active in WWTP effluent following UV disinfection

396 UV treatment significantly altered the effluent bacterial community in our WWTP

397 effluent samples. As a treatment designed to inactivate microorganisms (Hijnen et al. 2006), UV

398 disinfection indeed reduced the number of active OTUs and overall diversity (Shannon) in the

399 effluent in our study. Although a recent report showed that UV treatment has little effect on

400 microbial community composition in wastewater (Narciso-da-Rocha et al. 2018), several others

401 have shown reductions in both bacterial load (Glady-Croue et al. 2018), diversity (Kulkarni et al.

402 2018), and active/viable bacterial concentrations (Hu et al. 2016; Sullivan et al. 2017) following

403 UV exposure of wastewater. 
407 Instead, we observed a substantial reduction in the relative abundance of Bacteroidetes OTUs, specifically Cytophagaceae and Flavobacteriaceae, following UV disinfection, which is notable as members of this is phylum dominates both sewage and, to an even greater extent, human fecal microbiomes (Ahmed et al. 2017; Chu et al. 2018; McLellan et al. 2010); however, we did not

411 observe the typical sewage- and fecal-associated Bacteroidetes genus Bacteroides in our survey

412 of the active community. In addition, we were unable to detect members of the Lachnospiraceae

413 family, another sewage indicator group (McLellan et al. 2013), indicating that the WWTP used

414 here was sufficient at either removing, inactivating these organisms, or decreasing their

415 abundance substantially, even in the absence of disinfection. Therefore, the effects of UV

416 treatment on effluent microbial communities are shaped by the initial community, which will

417 vary between WWTPs based on treatment scheme and influent composition (Shchegolkova et al. 418 2016).

419 Some indicator bacteria (Legionella and Arcobacter) remained active following UV 420 treatment and were more abundant in the disinfected effluent than the untreated effluent. The 421 active fraction of the microbiome is therefore important in assessing effluent quality, as these are 422 the organisms with the potential to persist in the environment following discharge. In addition to 423 the two groups mentioned above, UV disinfection shifted the active community and increased 424 the relative abundance of several organisms, mostly associated with Proteobacteria. Many of 425 these, including Comamonadaceae, Pseudomonas, Moraxellaceae, and Rhodocyclaceae have 426 previously been identified as among the most abundant taxa in sewage and freshwater (Kulkarni 
427 et al. 2018; McLellan et al. 2010; Narciso-da-Rocha et al. 2018; Newton \& McLellan 2015).

428 Rhodocyclaceae in particular are common inhabitants of nutrient/substrate-rich environments

429 such as wastewater and impacted urban streams (Chaudhary et al. 2018). Comamonadaceae are

430 also abundant in freshwater environments (Balmonte et al. 2016; Shaw et al. 2008) and have

431 previously been found to dominate in Lake Michigan (Mueller-Spitz et al. 2009), the freshwater

432 source of the river we studied here. However, the OTUs affiliated with Comamonadaceae here

433 were predominantly unclassified genera, rather than the common freshwater Limnohabitans

434 (Hahn et al. 2010) and might instead be relative to WWTP-associated Comamonadaceae

435 involved in denitrification that are common in activated sludge systems such as the WWTP from 436 which we sampled (Khan et al. 2002).

Similar to what has been found in other wastewater surveys (Ahmed et al. 2017; Chu et

al. 2018; McLellan et al. 2010), Pseudomonas was not only one of the common and dominant members here. This group is also known to tolerate and grow following UV treatment (Glady-

440 Croue et al. 2018; Hu et al. 2016; Sullivan et al. 2017), which has been attributed to UV-

441 inducible genes and UV-resistance plasmids that are often carried by members of this group (Hu

442 et al. 2016; Kokjohn \& Miller 1994; Zhao et al. 2018). The other groups we saw active following

443 UV treatment have not been implicated in UV tolerance in wastewater disinfection previously,

444 but based on their abundances in the effluent studied here as well as in other WWTPs

445 (Shchegolkova et al. 2016), their growth following UV treatment is notable. The Moraxellaceae

446 family, in particular, includes the genus Acinetobacter, members of which can be either non-

447 pathogenic or opportunistic pathogens (Hare et al. 2012) and are also among the predominant

448 bacterial taxa in wastewater (Ahmed et al. 2017; Chu et al. 2018; McLellan et al. 2010). Some of

449 the Moraxellaceae OTUs we saw increase in relative abundance following UV treatment were 
450 attributed to this genus, and previous work has demonstrated that several members of this group

451 can survive UV exposure (Hare et al. 2012). In fact, we previously showed that Moraxellaceae

452 were abundant in effluent from two different WWTPs, both of which employ disinfection (Chu

453 et al. 2018). We therefore confirm the tolerance of several common wastewater microorganisms

454 to UV disinfection at a standard UV dosage and reveal others whose activity post-UV exposure

455 had not previously been documented.

456

457

Stormflow derived from UV-treated effluent differs from that derived from untreated effluent.

458 Despite the fact that WWTP effluent accounts for $\sim 70 \%$ of the river flow under base

459 conditions in the system we studied, the river is still inhabited by many typical freshwater

460 bacteria such as a variety of Actinobacteria including members of the ac1 clade of

461 actinomycetes, freshwater Pelagibacter, and Polynucleobacter (Hahn et al. 2011; Newton et al.

462 2011; Oh et al. 2011). These organisms might originate from Lake Michigan, the freshwater

463 source to the Chicago River, We previously observed an increase in the relative abundance of

464 numerous bacteria under stormflow conditions in this system, which coincided with more than

465 double the flow of non-disinfected effluent from the WWTP (Chaudhary et al. 2018). Freshwater

466 bacteria made up a greater proportion of the baseflow river community and decreased

467 significantly under actual stormflow conditions (Chaudhary et al. 2018), which is what we

468 observed here in the simulated stormflow and baseflow microcosms. Among the most significant

469 changes in microbial community composition previously examined was an increase in

470 Legionella in stormflow compared to baseflow river samples (Chaudhary et al. 2018). Since that

471 study was conducted, the O'Brien WWTP has implemented a UV disinfection process prior to

472 effluent discharge into the river. Here, we saw a notable increase in the Verrucomicrobia 
473 Prosthecobacter over time in both stormflow treatments compared to the baseflow, indicating

474 that this riverine organism might thrive on nutrients added with WWTP effluent (Hedlund et al.

475 1997). Although the two stormflow sample types did not differ much from each other initially,

476 by 48 h the microbial community compositions diverged significantly. As with the in situ study

477 (Chaudhary et al. 2018), we observed an increase in the relative abundance of Legionella in

478 stormflow samples with untreated effluent in our microcosms. Legionella might become

479 enriched during the WWTP chain (Kulkarni et al. 2018). Many other bacteria were also over-

480 represented in the untreated effluent-derived stormflow samples compared to those that received

481 UV-treated effluent. Several of these were the same organisms that survived and proliferated in

482 the effluent only samples, such as members of the Flavobacteria, Arcobacter, Bacteroidetes,

483 Sphingobacteriales, Cryomorphaceae, and Cytophagales. Similarly, Rhodocyclaceae, which was

484 also found enriched in UV-treated effluent, was over-represented in the UV-treated effluent-

485 derived stormflow samples. All of this indicates that the organisms that are released in WWTP

486 effluent can proliferate in the receiving water body, including those that have survived UV

487 treatment.

488

489

Changes in the microbiome are reflected in expression of specific functional genes

Along with microorganisms, wastewater is a common source of antibiotics and antibiotic

491 resistance genes to the environment, potentially creating an environmental hotspot and reservoir

492 for antimicrobial resistance (Barber et al. 2015; Chu et al. 2018; Mao et al. 2015; Rizzo et al.

493 2013; Tennstedt et al. 2003; Xu et al. 2015). Although UV photolytic degradation of antibiotics

494 can occur during disinfection and produce toxic photoproducts (Dann \& Hontela 2011; Guo et al.

495 2013a), bacteria susceptible to antibiotic photoproducts may obtain resistance by random

Peer] reviewing PDF | (2019:03:35970:2:0:NEW 17 Jun 2019) 
496 mutations or acquire resistant via horizontal gene transfer, which could possibly be one of the

497 reasons UV disinfection may shift the frequency of resistance genes in the effluent bacteria. In

498 fact, our group has recently shown that several ARGs and ARBs persist through wastewater

499 treatment with disinfection and these effluents are also enriched in mobile genetic elements (Chu

500 et al. 2018; Petrovich et al. 2018).

501 The occurrence of ARB and ARGs in effluent presents a challenge to applying the UV

502 disinfection process and conflicting results exist regarding its effectiveness at reducing ARB and

503 ARG loads, which seems to vary with different antibiotics and treatment schemes. One study

504 showed a reduction in ARBs following UV treatment (Narciso-da-Rocha et al. 2018) and

505 decrease in mecA and vanA ARGs after UV disinfection of wastewater was observed under

506 laboratory conditions (McKinney \& Pruden 2012). In contrast, UV dose did not reduce the

507 number of detectable tet gene types (tetracycline resistance) (Auerbach et al. 2007) nor did UV

508 disinfection contribute to significant reduction of tetracycline- and sulfonamide-resistant bacteria

509 concentrations in a full scale WWTP (Munir et al. 2011). More recently, several studies support

510 these latter findings that UV disinfection does not reduce tet $W$ genes and showed that it may

511 actually increase the relative abundance of some ARGs and ARBs in effluent (Glady-Croue et al.

512 2018; Guo et al. 2013b; Hu et al. 2016; Sullivan et al. 2017). Our results support these mixed

513 findings and provide additional insight by evaluating gene expression for several days after UV

514 treatment: expression of tet $W$ decreased immediately following UV exposure compared to

515 untreated effluent, but tet $W$ expression increased in the river 48 hours after the UV-treated

516 effluent addition as compared with the addition of non-UV treated effluent. Concurrent with

517 these results, the evidence of an increase in proteobacterial sequences, particularly Pseudomonas,

518 may suggest that bacteria harboring antibiotic resistant genes following UV treatment also 
519 possess mobile genetic elements, which enable the proliferation of ARGs in the environment.

520 Although we did not explore mobile elements here, previous studies indicate that mobile

521 elements can be enriched during treatment and correlate with ARGs (Chu et al. 2018; Hu et al.

522 2016; Petrovich et al. 2018; Wang et al. 2013).

523 WWTP effluents are also a source of high levels of organic matter and nutrients,

524 including ammonia (Brion \& Billen 2000; Servais et al. 1999) and are known to impact ammonia

525 oxidizing microorganisms in receiving waters (Carey \& Migliaccio 2009; Merbt et al. 2015).

526 Although UV treatment initially reduced the expression of amoA in effluent, expression levels

527 were the similar at the end of the incubation period. Furthermore, amo $A$ gene expression was

528 similar in the stormflow samples with treated and untreated effluent. Taken together, our results

529 suggest that like tet $W$ gene expression, the bacteria carrying out ammonia oxidation are resilient

530 to UV treatment $48 \mathrm{~h}$ after exposure. Photoinhibition (non-UV) of amo $A$ has been documented

531 previously (Merbt et al. 2017), but this is the first evaluation, to our knowledge, of nitrification

532 activity in effluent following UV exposure. Given that both $a m o A$ and tet $W$ gene expression

533 recover to levels similar to those in untreated effluent within $48 \mathrm{~h}$ of UV treatment, it is likely that

534 a wide variety of functions are resilient to UV treatment and can persist when introduced into the 535 surrounding environment.

537 Conclusions

538 In summary, UV exposure decreased the number of OTUs and the microbial diversity of effluent

539 discharged from a WWTP that did not employ a disinfection step before discharge into an urban

540 river. Several organisms remained active following UV exposure and were enriched relative to

541 untreated effluent, including Moraxellaceae, Pseudomonas, Comamonadaceae, and 
542 Rhodocyclaceae. When potential ecosystem-level effects were considered, stormflow-like river

543 samples with UV-treated effluent had fewer organisms like Enterobacteriaceae, Legionellaceae,

544 Arcobacter compared to stormflow with untreated effluent. At a functional level, UV treatment

545 initially decreased gene expression of both tet $W$ and amo $A$, but these funtions recovered over

546 time. Our study was based on a single sampling event at a single WWTP, so repetition would be

547 helpful for determining if our findings are representative of the plant over time or even of other

548 WWTPs. Additional functional analysis using metagenomics or metaproteomics would also add

549 a deeper understanding of UV effects on the microbial community. Despite these limitations, our

550 comparison of UV-treated and non-UV treated effluent using lab-scale disinfection experiments

551 provided insights into the effects of disinfection on the effluent total bacterial community and its

552 implication on the environment.

553

554 Acknowledgements

555 We thank the staff of the Metropolitan Water Reclamation District for facilitating sample

556 collection. Juana Villagomez provided technical assistance as a Bridges 2 Baccalaureate summer

557 student.

558

559 References

560

561

562

563

564

565

566

567

Abraham W-R. 2011. Megacities as sources for pathogenic bacteria in rivers and their fate downstream. International Journal of Microbiology 2011. 10.1155/2011/798292

Ahmed W, Staley C, Sidhu J, Sadowsky M, and Toze S. 2017. Amplicon-based profiling of bacteria in raw and secondary treated wastewater from treatment plants across Australia. Applied Microbiology and Biotechnology 101:1253-1266. 10.1007/s00253-016-7959-9

Aminov RI, Garrigues-Jeanjean N, and Mackie RI. 2001. Molecular ecology of tetracycline resistance: Development and validation of primers for detection of tetracycline resistance 
568

569

570

571

572

573

574

575

576

577

578

579

580

581

582

583

584

585

586

587

588

589

590

591

592

593

594

595

596

597

598

599

600

601

602

603

604

605

606

607

608

609

610

611

612 genes encoding ribosomal protection proteins. Applied and Environmental Microbiology 67:22-32. 10.1128/aem.67.1.22-32.2001

Andrews S. 2012. FastQC: A quality control application for high throughput sequence data. Babraham Institute Project page: www.bioinformatics.babraham.ac.uk/projects/fastqc/.

Auerbach EA, Seyfried EE, and McMahon KD. 2007. Tetracycline resistance genes in activated sludge wastewater treatment plants. Water Research 41:1143-1151.

10.1016/j.watres.2006.11.045

Ayarza JM, Figuerola EL, and Erijman L. 2014. Draft Genome Sequences of Type Strain Sediminibacterium salmoneum NJ-44 and Sediminibacterium sp. Strain C3, a Novel Strain Isolated from Activated Sludge. Genome Announcements 2. 10.1128/genomeA.01073-13

Balmonte JP, Arnosti C, Underwood S, McKee BA, and Teske A. 2016. Riverine bacterial communities reveal environmental disturbance signatures within the Betaproteobacteria and Verrucomicrobia. Frontiers in Microbiology 7. 10.3389/fmicb.2016.01441

Barber LB, Loyo-Rosales JE, Rice CP, Minarik TA, and Oskouie AK. 2015. Endocrine disrupting alkylphenolic chemicals and other contaminants in wastewater treatment plant effluents, urban streams, and fish in the Great Lakes and Upper Mississippi River Regions. Science of the Total Environment 517:195-206. 10.1016/j.scitotenv.2015.02.035

Bolger AM, Lohse M, and Usadel B. 2014. Trimmomatic: a flexible trimmer for Illumina sequence data. Bioinformatics 30:2114-2120. 10.1093/bioinformatics/btu170

Bolton JR, and Linden KG. 2003. Standardization of methods for fluence (UV dose) determination in bench-scale UV experiments. Journal of Environmental EngineeringASCE 129:209-215. 10.1061/(asce)0733-9372(2003)129:3(209)

Brion N, and Billen G. 2000. Wastewater as a source of nitrifying bacteria in river systems: the case of the River Seine downstream from Paris. Water Research 34:3213-3221. Doi 10.1016/S0043-1354(00)00075-0

Brooks BW, Riley TM, and Taylor RD. 2006. Water quality of effluent-dominated ecosystems: ecotoxicological, hydrological, and management considerations. Hydrobiologia 556:365379. 10.1007/s10750-004-0189-7

Caporaso JG, Kuczynski J, Stombaugh J, Bittinger K, Bushman FD, Costello EK, Fierer N, Pena AG, Goodrich JK, Gordon JI, Huttley GA, Kelley ST, Knights D, Koenig JE, Ley RE, Lozupone CA, McDonald D, Muegge BD, Pirrung M, Reeder J, Sevinsky JR, Tumbaugh PJ, Walters WA, Widmann J, Yatsunenko T, Zaneveld J, and Knight R. 2010. QIIME allows analysis of high-throughput community sequencing data. Nature Methods 7:335336. 10.1038/nmeth.f.303

Carey RO, and Migliaccio KW. 2009. Contribution of Wastewater Treatment Plant Effluents to Nutrient Dynamics in Aquatic Systems: A Review. Environmental Management 44:205217. 10.1007/s00267-009-9309-5

Chaudhary A, Kauser I, Ray A, and Poretsky R. 2018. Taxon-driven functional shifts associated with storm flow in an urban stream microbial community. mSphere 3.

10.1128/mSphere.00194-18

Chu BTT, Petrovich ML, Chaudhary A, Wright D, Murphy B, Wells G, and Poretsky R. 2018. Metagenomics reveals the impact of wastewater treatment plants on the dispersal of microorganisms and genes in aquatic sediments. Applied and Environmental Microbiology 84. 10.1128/aem.02168-17 
613 Dahllof I, Baillie H, and Kjelleberg S. 2000. rpoB-based microbial community analysis avoids

614 limitations inherent in 16S rRNA gene intraspecies heterogeneity. Applied and

615

616

617

618

619

620

621

622

623

624

625

626

627

628

629

630

631

632

633

634

635

636

637

638

639

640

641

642

643

644

645

646

647

648

649

650

651

652

653

654

655

656

657 Environmental Microbiology 66:3376-3380. 10.1128/aem.66.8.3376-3380.2000

Dann AB, and Hontela A. 2011. Triclosan: environmental exposure, toxicity and mechanisms of action. Journal of Applied Toxicology 31:285-311. 10.1002/jat.1660

De Vrieze J, Pinto AJ, Sloan WT, and Ijaz UZ. 2018. The active microbial community more accurately reflects the anaerobic digestion process: $16 \mathrm{~S}$ rRNA (gene) sequencing as a predictive tool. Microbiome 6:63. 10.1186/s40168-018-0449-9

Di Cesare A, Fontaneto D, Doppelbauer J, and Corno G. 2016. Fitness and recovery of bacterial communities and antibiotic resistance genes in urban wastewaters exposed to classical disinfection treatments. Environmental Science \& Technology 50:10153-10161. 10.1021/acs.est.6b02268

Drury B, Rosi-Marshall E, and Kelly JJ. 2013. Wastewater treatment effluent reduces the abundance and diversity of benthic bacterial communities in urban and suburban rivers. Applied and Environmental Microbiology 79:1897-1905. 10.1128/aem.03527-12

Edgar RC, Haas BJ, Clemente JC, Quince C, and Knight R. 2011. UCHIME improves sensitivity and speed of chimera detection. Bioinformatics 27:2194-2200. 10.1093/bioinformatics/btr381

Fisher JC, Levican A, Figueras MJ, and McLellan SL. 2014. Population dynamics and ecology of Arcobacter in sewage. Frontiers in Microbioly 5:525. 10.3389/fmicb.2014.00525

Frank JA, Reich CI, Sharma S, Weisbaum JS, Wilson BA, and Olsen GJ. 2008. Critical evaluation of two primers commonly used for amplification of bacterial $16 \mathrm{~S}$ rRNA genes. Applied and Environmental Microbiology 74:2461-2470. 10.1128/aem.02272-07

Garcia-Armisen T, Touron A, Petit F, and Servais P. 2005. Sources of faecal contamination in the Seine estuary (France). Estuaries 28:627-633. 10.1007/bf02696073

Glady-Croue J, Niu X-Z, Ramsay JP, Watkin E, Murphy RJT, and Croue J-P. 2018. Survival of antibiotic resistant bacteria following artificial solar radiation of secondary wastewater effluent. Science of the Total Environment 626:1005-1011.

Goñi-Urriza M, Capdepuy M, Raymond N, Quentin C, and Caumette P. 1999. Impact of an urban effluent on the bacterial community structure in the Arga River (Spain), with special reference to culturable Gram-negative rods. Canadian Journal of Microbiology 45:826-832. 10.1139/cjm-45-10-826

Gücker B, Brauns M, and Pusch MT. 2006. Effects of wastewater treatment plant discharge on ecosystem structure and function of lowland streams. Journal of the North American Benthological Society 25:313-329.

Guo H-G, Gao N-Y, Chu W-H, Li L, Zhang Y-J, Gu J-S, and Gu Y-L. 2013a. Photochemical degradation of ciprofloxacin in UV and UV/H2O2 process: kinetics, parameters, and products. Environmental Science and Pollution Research 20:3202-3213. 10.1007/s11356012-1229-X

Guo M-T, Yuan Q-B, and Yang J. 2013b. Microbial selectivity of UV treatment on antibioticresistant heterotrophic bacteria in secondary effluents of a municipal wastewater treatment plant. Water Research 47:6388-6394. 10.1016/j.watres.2013.08.012

Hahn MW, Kasalický V, Jezbera J, Brandt U, Jezberova J, and Šimek K. 2010. Limnohabitans curvus gen. nov., sp. nov., a planktonic bacterium isolated from a freshwater lake. International Journal of Systematic and Evolutionary Microbiology 60:1358.

Peer] reviewing PDF | (2019:03:35970:2:0:NEW 17 Jun 2019) 
658

659

660

661

662

663

664

665

666

667

668

669

670

671

672

673

674

675

676

677

678

679

680

681

682

683

684

685

686

687

688

689

690

691

692

693

694

695

696

697

698

699

700

701
Hahn MW, Lang E, Brandt U, and Spröer C. 2011. Polynucleobacter acidiphobus sp. nov., a representative of an abundant group of planktonic freshwater bacteria. International Journal of Systematic and Evolutionary Microbiology 61:788.

Hare JM, Bradley JA, Lin C-1, and Elam TJ. 2012. Diverse responses to UV light exposure in Acinetobacter include the capacity for DNA damage-induced mutagenesis in the opportunistic pathogens Acinetobacter baumannii and Acinetobacter ursingii. Microbiology (Reading, England) 158:601-611. 10.1099/mic.0.054668-0

Hedlund BP, Gosink JJ, and Staley JT. 1997. Verrucomicrobia div. nov., a new division of the bacteria containing three new species of Prosthecobacter. Antonie Van Leeuwenhoek 72:29-38.

Hijnen WAM, Beerendonk EF, and Medema GJ. 2006. Inactivation credit of UV radiation for viruses, bacteria and protozoan (oo)cysts in water: A review. Water Research 40:3-22.

Hu Q, Zhang X-X, Jia S, Huang K, Tang J, Shi P, Ye L, and Ren H. 2016. Metagenomic insights into ultraviolet disinfection effects on antibiotic resistome in biologically treated wastewater. Water Research 101:309-317.

Illinois Department of Natural Resources. 2011. Illinois Coastal Management Program issue paper: Chicago River and North Shore Channel corridors.

Jumpstart Consortium Human Microbiome Project Data Generation Working G. 2012. Evaluation of 16S rDNA-based community profiling for human microbiome research. PloS one 7:e39315-e39315. 10.1371/journal.pone.0039315

Khan ST, Horiba Y, Yamamoto M, and Hiraishi A. 2002. Members of the Family Comamonadaceae as Primary Poly(3-Hydroxybutyrate-co-3-Hydroxyvalerate)Degrading Denitrifiers in Activated Sludge as Revealed by a Polyphasic Approach. Applied and Environmental Microbiology 68:3206-3214. 10.1128/aem.68.7.32063214.2002

Knights D, Costello EK, and Knight R. 2011. Supervised classification of human microbiota. FEMS Microbiology Reviews 35:343-359. 10.1111/j.1574-6976.2010.00251.x

Kokjohn TA, and Miller RV. 1994. IncN plasmids mediate UV resistance and errorprone repair in Pseudomonas aeruginosa PAO. Microbiology 140:43-48.

Kulkarni P, Olson ND, Paulson JN, Pop M, Maddox C, Claye E, Goldstein RER, Sharma M, Gibbs SG, Mongodin EF, and Sapkota AR. 2018. Conventional wastewater treatment and reuse site practices modify bacterial community structure but do not eliminate some opportunistic pathogens in reclaimed water. Science of the Total Environment 639:11261137. 10.1016/j.scitotenv.2018.05.178

Langille MGI, Zaneveld J, Caporaso JG, McDonald D, Knights D, Reyes JA, Clemente JC, Burkepile DE, Thurber RLV, Knight R, Beiko RG, and Huttenhower C. 2013. Predictive functional profiling of microbial communities using $16 \mathrm{~S}$ rRNA marker gene sequences. Nature Biotechnology 31:814-+. 10.1038/nbt.2676

Liang R, Liu H, Tao F, Liu Y, Ma C, Liu X, and Liu J. 2012. Genome sequence of Pseudomonas putida strain SJTE-1, a bacterium capable of degrading estrogens and persistent organic pollutants. Journal of Bacteriology 194:4781-4782. 10.1128/jb.01060-12

Linden KG, Shin GA, Faubert G, Cairns W, and Sobsey MD. 2002. UV disinfection of Giardia lamblia cysts in water. Environmental Science \& Technology 36:2519-2522. 10.1021/es0113403 
702

703

704

705

706

707

708

709

710

711

712

713

714

715

716

717

718

719

720

721

722

723

724

725

726

727

728

729

730

731

732

733

734

735

736

737

738

739

740

741

742

743

744

745
Livak KJ, and Schmittgen TD. 2001. Analysis of relative gene expression data using real-time quantitative PCR and the 2(T)(-Delta Delta C) method. Methods 25:402-408. 10.1006/meth.2001.1262

Love M, Anders S, and Huber W. 2013. Differential analysis of RNA-Seq data at the gene level using the DESeq2 package. Genome Biology 15.

Mao DQ, Yu S, Rysz M, Luo Y, Yang FX, Li FX, Hou J, Mu QH, and Alvarez PJJ. 2015. Prevalence and proliferation of antibiotic resistance genes in two municipal wastewater treatment plants. Water Research 85:458-466. 10.1016/j.watres.2015.09.010

Metropolitan Water Reclamation District of Greater Chicago. 2011. Evaluation of Disinfection Technologies for the Calumet and North Side Water Reclamation Plants.

McKinney CW, and Pruden A. 2012. Ultraviolet Disinfection of Antibiotic Resistant Bacteria and Their Antibiotic Resistance Genes in Water and Wastewater. Environmental Science \& Technology 46:13393-13400. 10.1021/es303652q

McLellan SL, Huse SM, Mueller-Spitz SR, Andreishcheva EN, and Sogin ML. 2010. Diversity and population structure of sewage-derived microorganisms in wastewater treatment plant influent. Environmental Microbiology 12:378-392. 10.1111/j.14622920.2009.02075.x

McLellan SL, Newton RJ, Vandewalle JL, Shanks OC, Huse SM, Eren AM, and Sogin ML. 2013. Sewage reflects the distribution of human faecal Lachnospiraceae. Environmental Microbiology 15:2213-2227. 10.1111/1462-2920.12092

McMurdie PJ, and Holmes S. 2013. phyloseq: An R Package for Reproducible Interactive Analysis and Graphics of Microbiome Census Data. PloS one 8. 10.1371/journal.pone.0061217

Merbt SN, Auguet JC, Blesa A, Marti E, and Casamayor EO. 2015. Wastewater treatment plant effluents change abundance and composition of ammonia-oxidizing microorganisms in mediterranean urban stream biofilms. Microbial Ecology 69:66-74. 10.1007/s00248-0140464-8

Merbt SN, Bernal S, Proia L, Martí E, and Casamayor EO. 2017. Photoinhibition on natural ammonia oxidizers biofilm populations and implications for nitrogen uptake in stream biofilms. Limnology and Oceanography 62:364-375.

Meziti A, Tsementzi D, Kormas KA, Karayanni H, and Konstantinidis KT. 2016. Anthropogenic effects on bacterial diversity and function along a river-to-estuary gradient in Northwest Greece revealed by metagenomics. Environmental Microbiology 18:4640-4652. 10.1111/1462-2920.13303

Mueller-Spitz SR, Goetz GW, and McLellan SL. 2009. Temporal and spatial variability in nearshore bacterioplankton communities of Lake Michigan. FEMS Microbiology Ecology 67:511-522. 10.1111/j.1574-6941.2008.00639.x

Munir M, Wong K, and Xagoraraki I. 2011. Release of antibiotic resistant bacteria and genes in the effluent and biosolids of five wastewater utilities in Michigan. Water Research 45:681-693. 10.1016/j.watres.2010.08.033

Narciso-da-Rocha C, Rocha J, Vaz-Moreira I, Lira F, Tamames J, Henriques I, Martinez JL, and Manaia CM. 2018. Bacterial lineages putatively associated with the dissemination of antibiotic resistance genes in a full-scale urban wastewater treatment plant. Environment International 118:179-188. 10.1016/j.envint.2018.05.040

Peer] reviewing PDF | (2019:03:35970:2:0:NEW 17 Jun 2019) 
746

747

748

749

750

751

752

753

754

755

756

757

758

759

760

761

762

763

764

765

766

767

768

769

770

771

772

773

774

775

776

777

778

779

780

781

782

783

784

785

786

787

788

789

790

Newton RJ, Jones SE, Eiler A, McMahon KD, and Bertilsson S. 2011. A guide to the natural history of freshwater lake bacteria. Microbiology and Molecular Biology Reviews 75:1449. 10.1128/MMBR.00028-10

Newton RJ, and McLellan SL. 2015. A unique assemblage of cosmopolitan freshwater bacteria and higher community diversity differentiate an urbanized estuary from oligotrophic Lake Michigan. Frontiers in Microbiology 6:1028. 10.3389/fmicb.2015.01028

Oh S, Caro-Quintero A, Tsementzi D, Deleon-Rodriguez N, Luo C, Poretsky R, and Konstantinidis KT. 2011. Metagenomic insights into the evolution, function, and complexity of the planktonic microbial community of lake lanier, a temperate freshwater ecosystem. Applied and Environmental Microbiology 77:6000-6011.

Parks DH, Tyson GW, Hugenholtz P, and Beiko RG. 2014. STAMP: statistical analysis of taxonomic and functional profiles. Bioinformatics 30:3123-3124. 10.1093/bioinformatics/btu494

Petrovich M, Chu B, Wright D, Griffin J, Elfeki M, Murphy BT, Poretsky R, and Wells G. 2018. Antibiotic resistance genes show enhanced mobilization through suspended growth and biofilm-based wastewater treatment processes. FEMS Microbiology Ecology 94. 10.1093/femsec/fiy174

Polls I, Luehing C, Zenz DR, and Sedita SJ. 1980. Effects of urban runoff and treated municipal wastewater on a man-made channel in northeastern Illinois. Water Research 14:207-215. 10.1016/0043-1354(80)90090-1

Price JR, Ledford SH, Ryan MO, Toran L, and Sales CM. 2018. Wastewater treatment plant effluent introduces recoverable shifts in microbial community composition in receiving streams. Science of the Total Environment 613:1104-1116. 10.1016/j.scitotenv.2017.09.162

Ramond J-B, Berthe T, Duran R, and Petit F. 2009. Comparative effects of mercury contamination and wastewater effluent input on Gram-negative merA gene abundance in mudflats of an anthropized estuary (Seine, France): a microcosm approach. Research in Microbiology 160:10-18. 10.1016/j.resmic.2008.10.004

Rizzo L, Manaia C, Merlin C, Schwartz T, Dagot C, Ploy MC, Michael I, and Fatta-Kassinos D. 2013. Urban wastewater treatment plants as hotspots for antibiotic resistant bacteria and genes spread into the environment: A review. Science of the Total Environment 447:345360. 10.1016/j.scitotenv.2013.01.032

Rotthauwe JH, Witzel KP, and Liesack W. 1997. The ammonia monooxygenase structural gene amoA as a functional marker: Molecular fine-scale analysis of natural ammoniaoxidizing populations. Applied and Environmental Microbiology 63:4704-4712.

Schlüter A, Szczepanowski R, Puehler A, and Top EM. 2007. Genomics of IncP-1 antibiotic resistance plasmids isolated from wastewater treatment plants provides evidence for a widely accessible drug resistance gene pool. FEMS Microbiology Reviews 31:449-477. 10.1111/j.1574-6976.2007.00074.x

Segata N, and Huttenhower C. 2011. Toward an efficient method of identifying core genes for evolutionary and functional microbial phylogenies. PloS one 6:e24704. 10.1371/journal.pone.0024704

Segata N, Izard J, Waldron L, Gevers D, Miropolsky L, Garrett WS, and Huttenhower C. 2011. Metagenomic biomarker discovery and explanation. Genome Biol 12:R60. 10.1186/gb2011-12-6-r60

Peer] reviewing PDF | (2019:03:35970:2:0:NEW 17 Jun 2019) 
791

792

793

794

795

796

797

798

799

800

801

802

803

804

805

806

807

808

809

810

811

812

813

814

815

816

817

818

819

820

821

822

823

824

825

826

827

828

829
Servais P, Garnier J, Demarteau N, Brion N, and Billen G. 1999. Supply of organic matter and bacteria to aquatic ecosystems through waste water effluents. Water Research 33:35213531. Doi 10.1016/S0043-1354(99)00056-1

Shaw AK, Halpern AL, Beeson K, Tran B, Venter JC, and Martiny JBH. 2008. It's all relative: ranking the diversity of aquatic bacterial communities. Environmental Microbiology 10:2200-2210. 10.1111/j.1462-2920.2008.01626.x

Shchegolkova NM, Krasnov GS, Belova AA, Dmitriev AA, Kharitonov SL, Klimina KM, Melnikova NV, and Kudryavtseva AV. 2016. Microbial community structure of activated sludge in treatment plants with different wastewater compositions. Frontiers in Microbiology 7. 10.3389/fmicb.2016.00090

Sullivan BA, Vance CC, Gentry TJ, and Karthikeyan R. 2017. Effects of chlorination and ultraviolet light on environmental tetracycline-resistant bacteria and tet(W) in water. Journal of Environmental Chemical Engineering 5:777-784.

Tennstedt T, Szczepanowski R, Braun S, Puhler A, and Schluter A. 2003. Occurrence of integron-associated resistance gene cassettes located on antibiotic resistance plasmids isolated from a wastewater treatment plant. FEMS Microbiology Ecology 45:239-252. 10.1016/s0168-6496(03)00164-8

United States Environmental Protection Agency, Office of Water. 2009. Drinking water infrastructure needs survey and assessment: fourth report to Congress. EPA 816-K-17002

United States Environmental Protection Agency, Office of Water. 2018. Final 2016 Effluent Guidelines Program Plan. Washington, D.C. EPA-821-R-18-001

Waiser MJ, Tumber V, and Holm J. 2011. Effluent-dominated streams. Part 1: Presence and effects of excess nitrogen and phosphorus in Wascana Creek, Saskatchewan, Canada. Environmental Toxicology and Chemistry 30:496-507. 10.1002/etc.399

Walsh F, Ingenfeld A, Zampicolli M, Hilber-Bodmer M, Frey JE, and Duffy B. 2011. Real-time PCR methods for quantitative monitoring of streptomycin and tetracycline resistance genes in agricultural ecosystems. Journal of Microbiological Methods 86:150-155. 10.1016/j.mimet.2011.04.011

Wang Z, Zhang X-X, Huang K, Miao Y, Shi P, Liu B, Long C, and Li A. 2013. Metagenomic profiling of antibiotic resistance genes and mobile genetic elements in a tannery wastewater treatment plant. PloS one 8. 10.1371/journal.pone.0076079

Xu J, Xu Y, Wang H, Guo C, Qiu H, He Y, Zhang Y, Li X, and Meng W. 2015. Occurrence of antibiotics and antibiotic resistance genes in a sewage treatment plant and its effluentreceiving river. Chemosphere 119:1379-1385. 10.1016/j.chemosphere.2014.02.040

Zhao F, Hu Q, Ren H, and Zhang X-X. 2018. Ultraviolet irradiation sensitizes Pseudomonas aeruginosa PAO1 to multiple antibiotics. Environmental Science: Water Research \& Technology 4:2051-2057. 
Figure 1 (on next page)

Alpha diversity (Shannon diversity index) among the five experimental treatments.

Figure 1. Alpha diversity (Shannon diversity index) among the five experimental treatments. The diversity at $0 \mathrm{~h}$ (red), $24 \mathrm{~h}$ (green), and $48 \mathrm{~h}$ (blue) included for each condition with two replicates per time point. Stormflow samples indicate effluent additions to river water. The bold lines indicate median values for the six samples from each treatment. 


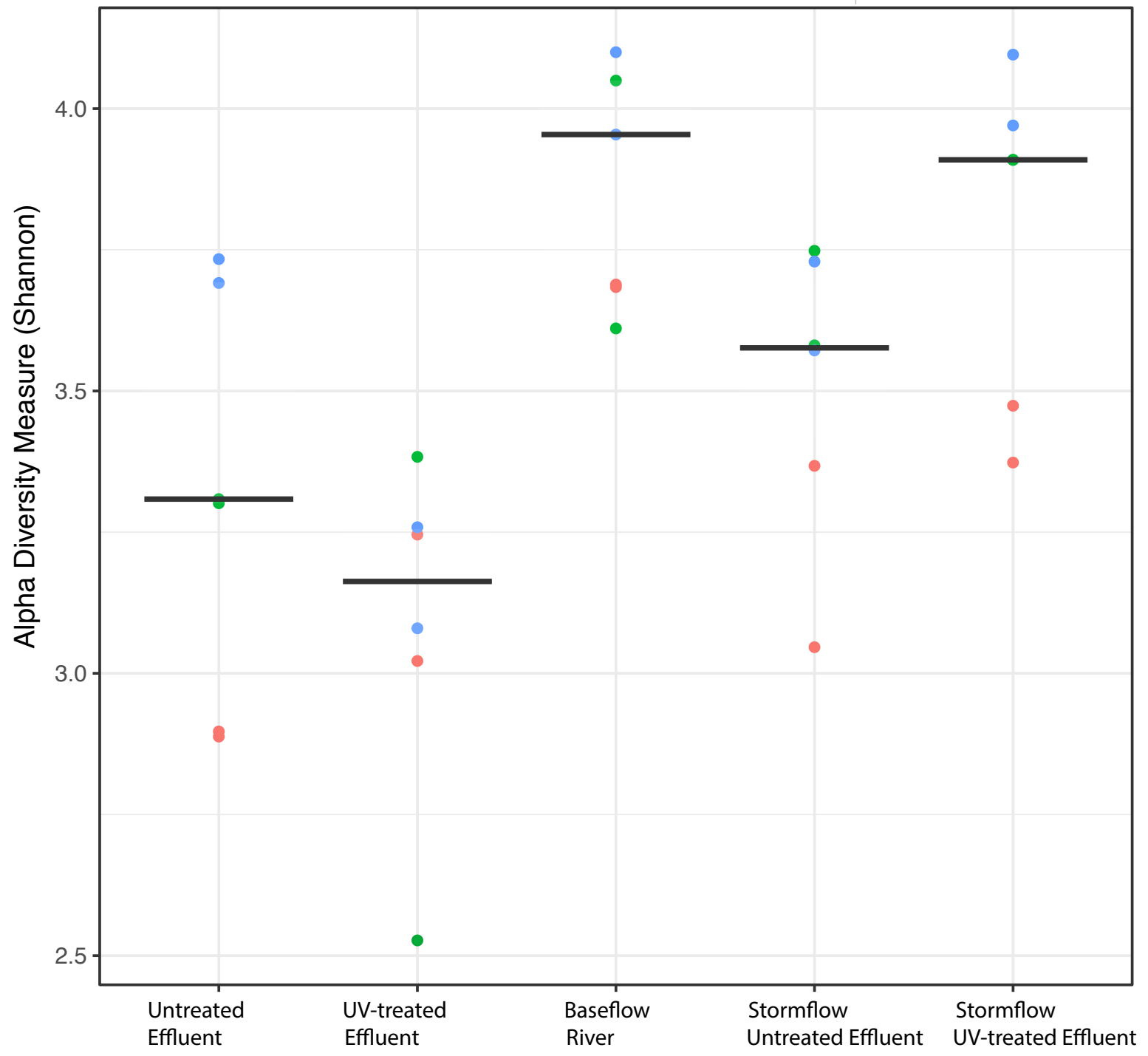

Hours

- Oh

- $24 \mathrm{~h}$

- $48 h$ 
Figure 2 (on next page)

Principle coordinates analysis (PCoA) ordination on Bray-Curtis distances of microbial communities.

(A) untreated (red) and UV-treated (green) effluent-only microcosms and (B) baseflow river water (blue), stormwater-like samples with untreated effluent (red), and stormwater-like samples with UV-treated effluent (green) at $0 \mathrm{~h}$ (circles), $24 \mathrm{~h}$ (triangles), and $48 \mathrm{~h}$ (squares). 

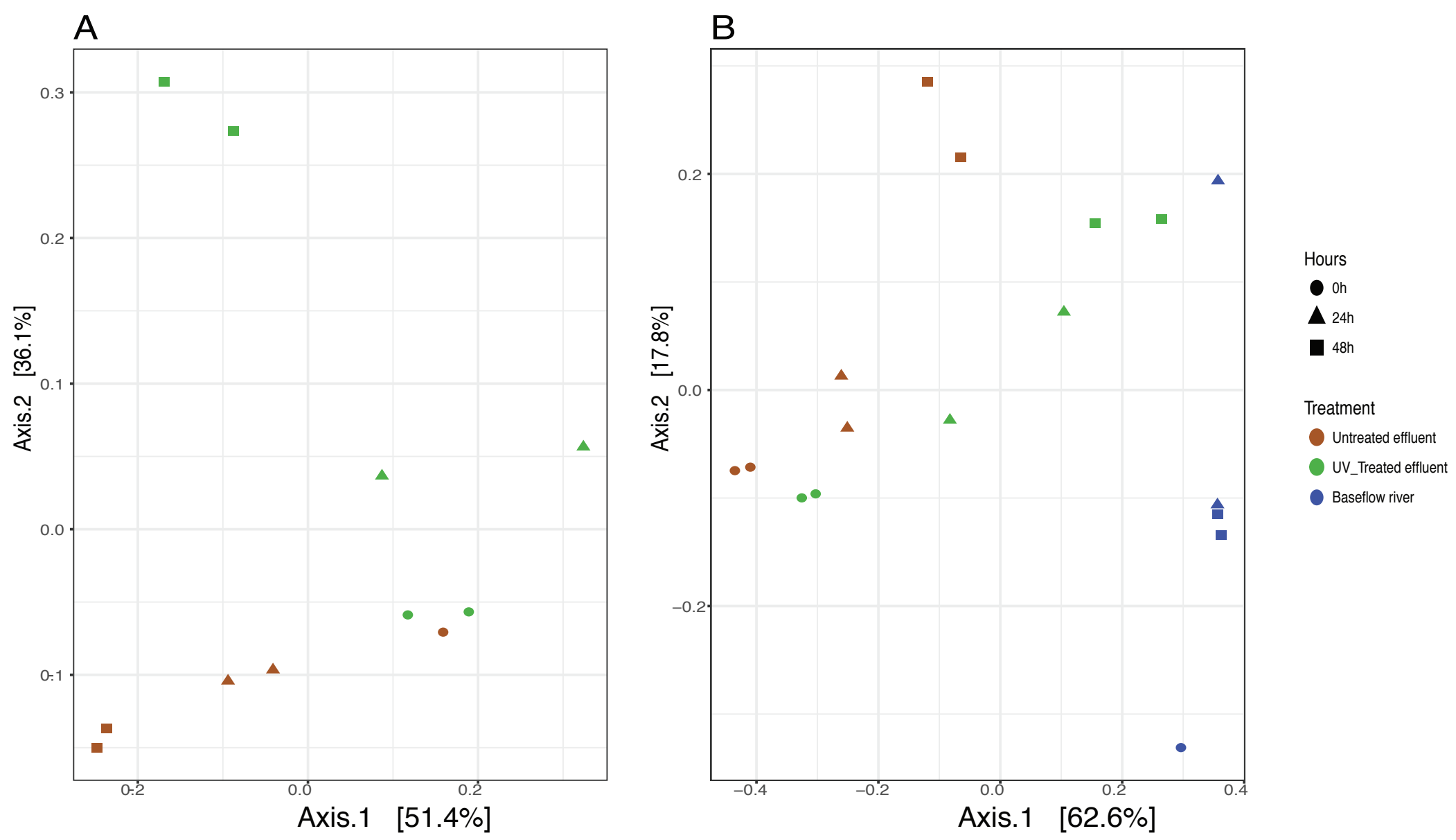


\section{Figure $\mathbf{3}$ (on next page)}

Taxonomic distribution of OTUs at the phylum level for the four phyla with a total of $>1 \%$ of the OTUs in all samples.

Relative abundance refers to percentage of the OTUs attributed to each phylum with respect to all OTUs from each sample, including those that were unclassified. The Proteobacteria bars are subdivided into Alpha-, Beta-, Epsilon-, and Gammaproteobacteria. The five sample types are separated vertically by treatment (A-C: untreated effluent; D-F: UV-treated effluent; G-I: river water; J-L: river with added untreated effluent; M-O: river with added UV-treated effluent) and horizontally by time point (0h, 24h, 48h). 


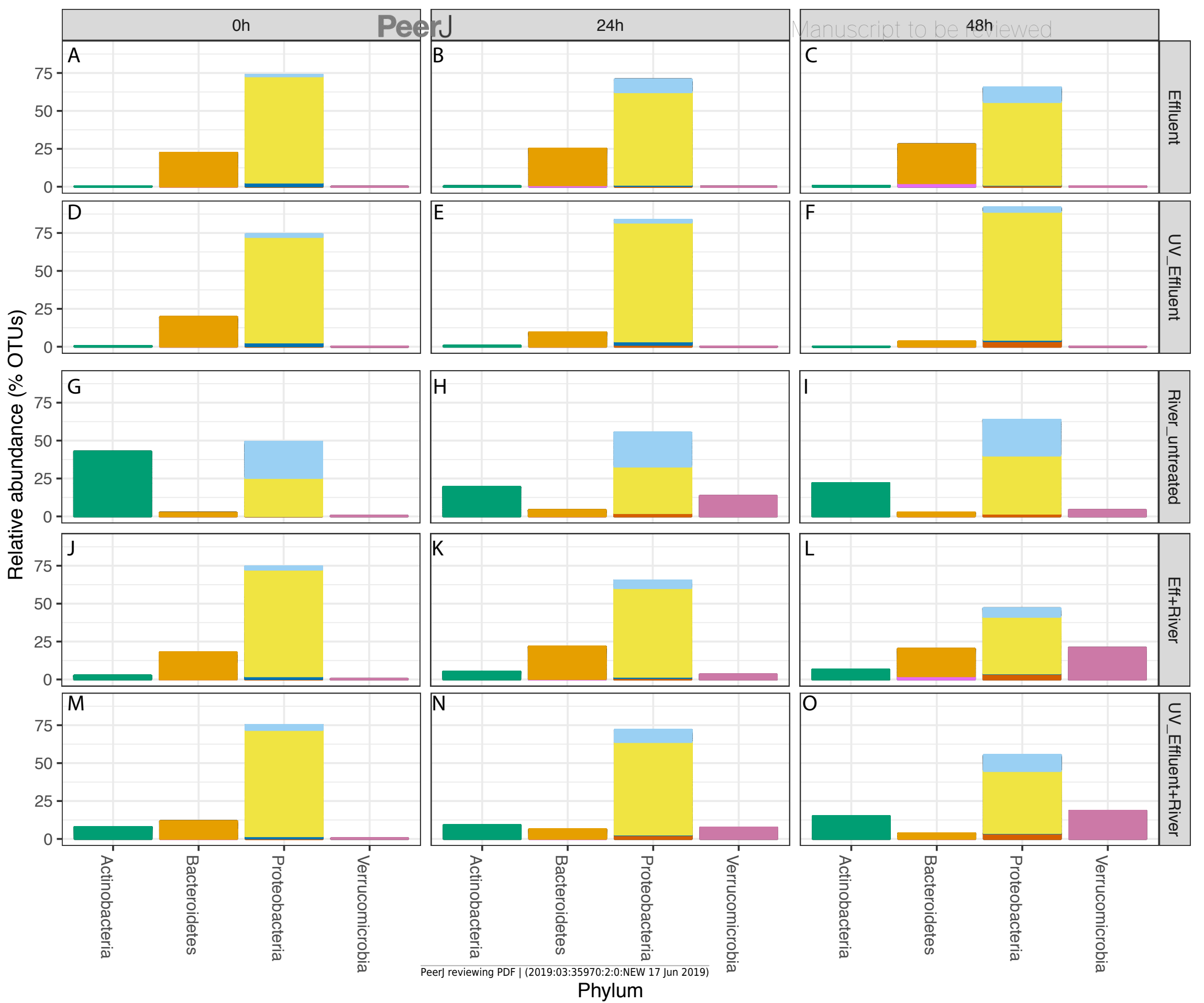

Alphaproteobacteria

Betaproteobacteria

Epsilonproteobacteria

Gammaproteobacteria 
Figure 4 (on next page)

LDA scores calculated by LEfSe of differentially abundant taxa.

(A) untreated effluent (red) compared to UV-treated effluent samples (green) and (B) baseflow river (blue) compared to stormflow-like samples with untreated effluent (red) and stormflow-like samples with UV-treated effluent (green). All time points were combined for these analyses. 


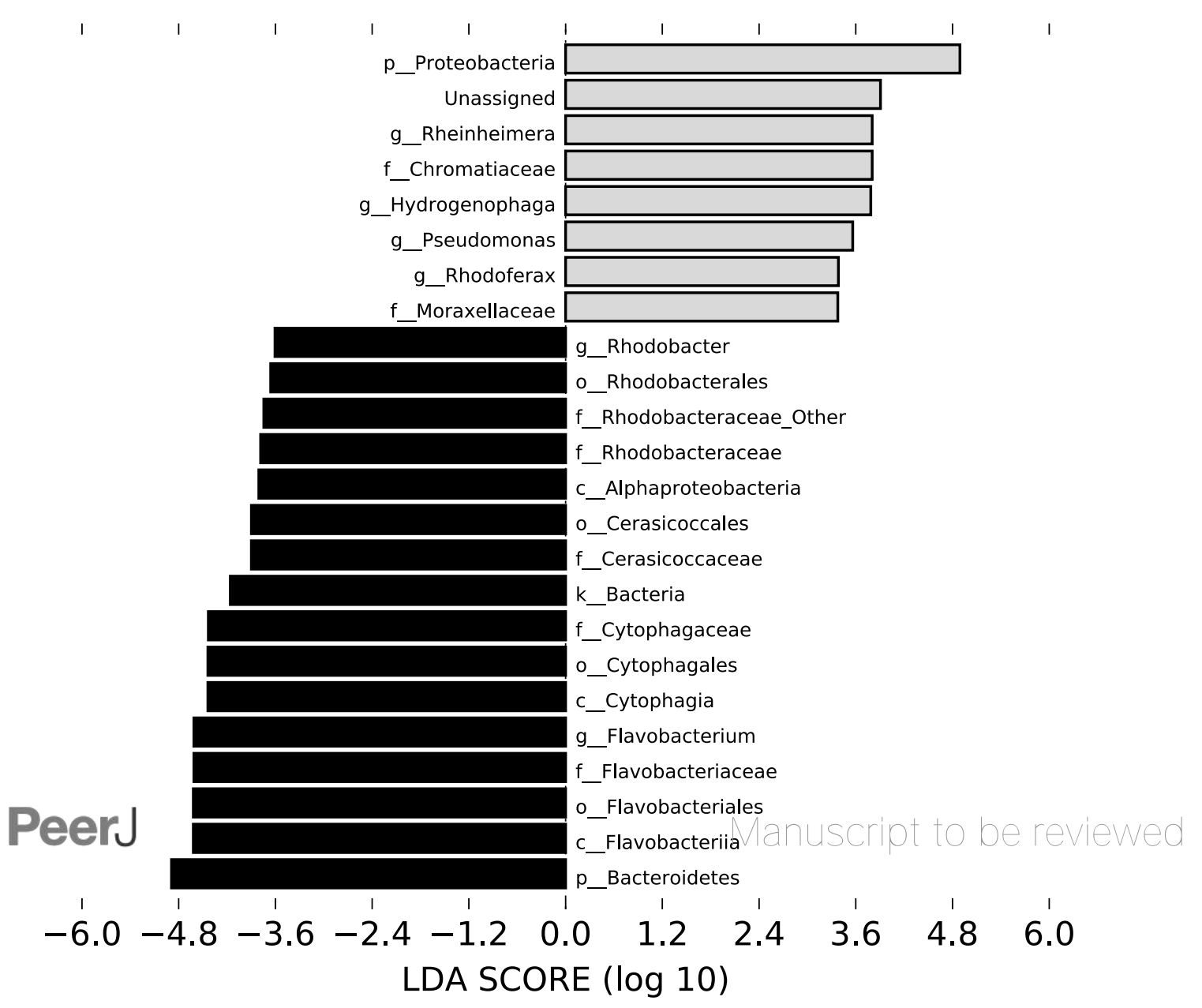

B
$\square$ Stormflow
Untreated effluent
Stormflow
$\square$ Baseflow river

f_Rhodocyclaceae f_Oxalobacteraceae_other f_Oxalobacteraceae

P_Actinobacteria

C_Actinobacteria

f_ACK_M1

f_Pelagibacteraceae f_Caulobacteraceae_Other

o_Actinomycetales

g_Ramlibacter

- Burkholderiales Other

g_Polynucleobacter

Microbacteriaceae

g Rhodoferax

f_Microbacteriaceae_Other o_Actinomycetales_other

f_Procabacteriaceae

o_Procabacteriales

p_Bacteroidetes

C_Betaproteobacteria_Other

O_Flavobacteriales

c Flavobacteriia

g_Flavobacterium

$f$ Flavobacteriaceae

f_Cytophagaceae

o_Cytophagales

C_Cytophagia

g_Desulfovibrio

o_Desulfovibrionales

$f$ Enterobacteriaceae

O_Enterobacteriales

c_Sphingobacteriia

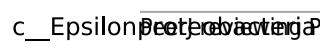

o_Campylobacterales

o_Sphingobacteriales

f_Desulfovibrionaceae

g_Rubrivivax

C_Deltaproteobacteria

g_Arcobacter

f_Legionellaceae

g_C39

o_Rickettsiales

Rhodobacteraceae Other

c_Alphaproteobacteria_Other

g_Bdellovibrio

$f$ Bdellovibrionaceae

o_Bdellovibrionales

$$
\text { o_Ellin329 }
$$

f_Rickettsiaceae

f_Campylobacteraceae

g_Sulfurospirillum

f_Weeksellaceae

g_Cloacibacterium
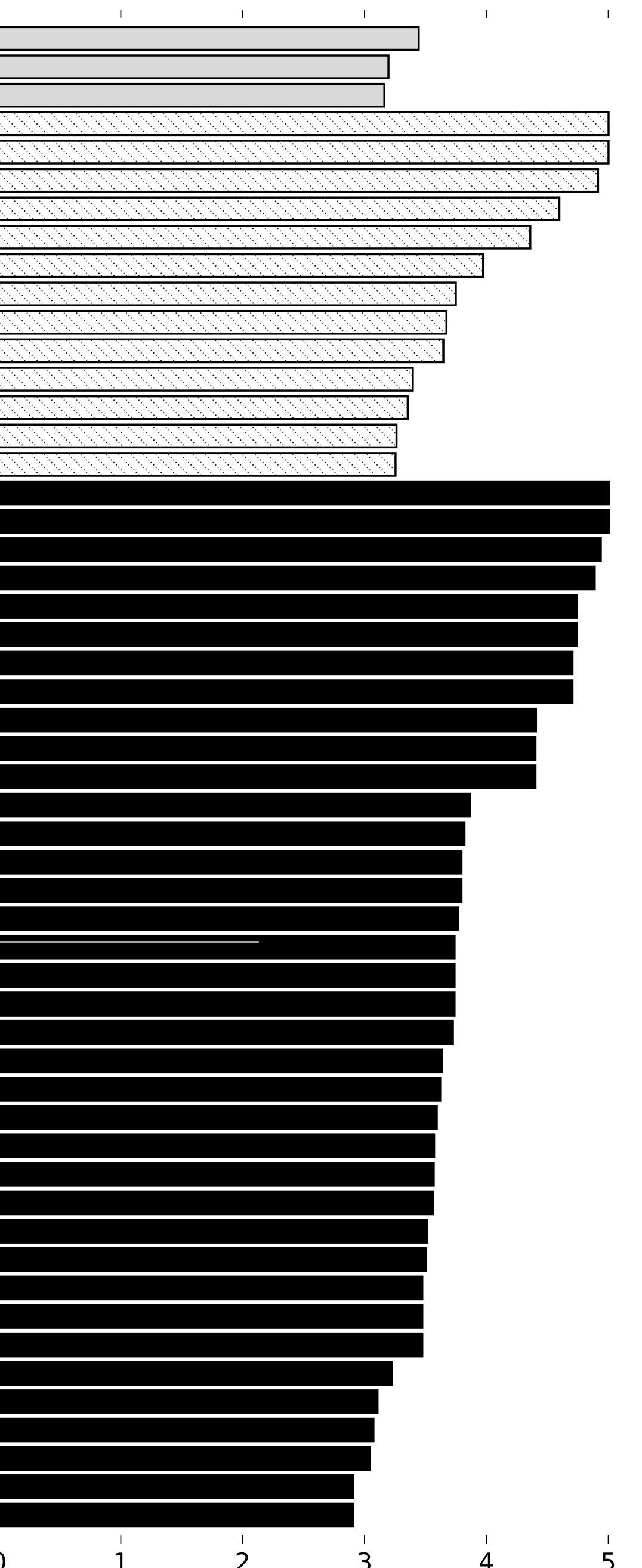

LDA SCORE $(\log 10)$ 
Figure $\mathbf{5}$ (on next page)

RT-qPCR-based quantification of $a m o A$ and tetW gene expression relative to rpoB gene expression derived from $\mathrm{Cq}$ values.

Expression of amoA (A) and tetW (B) in untreated (black) and UV-treated (white) effluent-only microcosms and amoA (C) and tetW (D) in stormwater-like samples with untreated effluent (black), and stormwater-like samples with UV-treated effluent (white) at $0 \mathrm{~h}, 24 \mathrm{~h}$, and $48 \mathrm{~h}$ (two samples from each time point). Error bars indicate standard error from triplicate RTqPCRs. Letters denote significantly different samples based on ANOVA and Tukey's 'Honest Significant Difference' tests. 

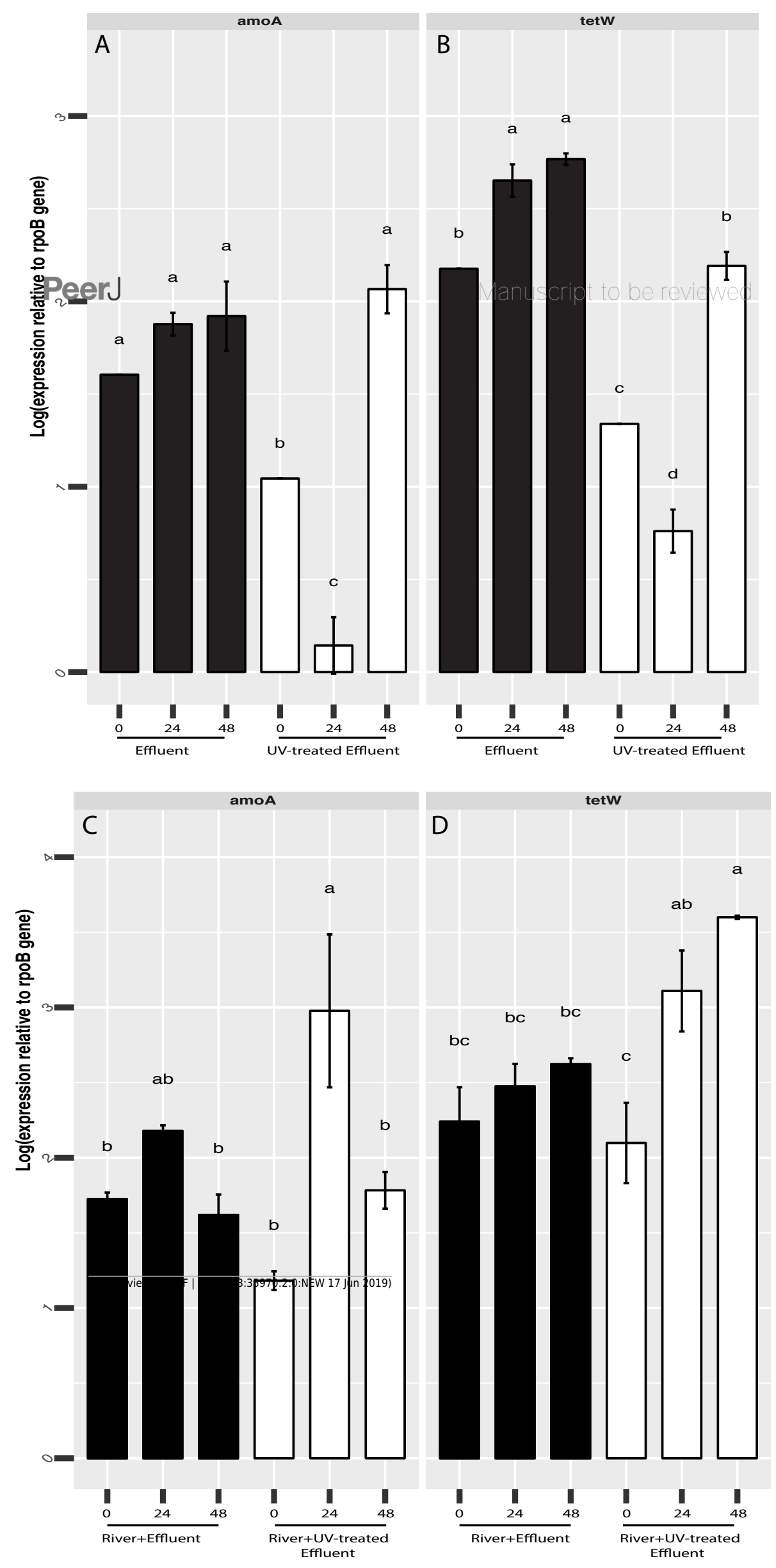